\title{
The Creativity Canvas: A Business Model for Knowledge and Idea Management Raouf Naggar
}

\author{
"We must cultivate our garden." \\ Voltaire (1694-1778) \\ In Candide, or All for the Best
}

\begin{abstract}
Innovation depends on ideas generated through creativity and the knowledge and research that make it possible to put ideas to work. However, these two activities are very dependent on the people who perform them. As demonstrated by a pilot project realized at HydroQuébec's research institute (IREQ), any approach that does not take this understanding into account is doomed to failure. This article proposes that what must be developed is a knowledge and idea management system designed as a coherent ecosystem that takes all controlling factors into account and is based on stakeholder interest and preferences. This ecosystem is the result of a meticulous design of each of the elements that must generally be taken into account in a business model. A business model approach includes not only developing a value proposition for knowledge and idea management that suits the target clientele but also a good understanding of the resources and activities required to deliver this value proposition and especially the ways to finance them. Key to the development of such an ecosystem is the creation of fully functional innovation communities, which are responsible for building up and nurturing their ideas and knowledge assets and getting value out of them.
\end{abstract}

\section{Introduction}

Creativity plays an essential role in the innovation process because it generates the ideas that will initiate innovation. Ideas emerge at every level of the process and they correspond to various challenges, such as responding to an issue, meeting a target objective, solving a problem, making use of knowledge, or understanding a phenomenon. But it is knowledge that makes it possible to put ideas to work and hence to innovate. In addition, knowledge feeds creativity, and ideas stimulate research. Thus, the success of innovation relies largely on these two activities, which are very dependent on people who perform them.

The need to concomitantly manage both knowledge and ideas has been a key innovation management challenge at the Institut de recherche d'Hydro-Québec (IREQ; tinyurl.com/pcodg52), a research institute to support Hydro-Québec, the government-owned public utility that generates, transmits, and distributes electricity throughout the Canadian province of Quebec. IREQ has approximately 500 staff, including scientists, technicians, engineers, and specialists. The Institute's work covers the five following priority fields: i) the smart grid, ii) the aging of materials and long-term viability of facilities, iii) the efficient use of electricity, iv) renewable energy, and v) battery materials and electric transportation. IREQ owes its existence to the success of its innovations and thus to the creativity, knowledge and know-how of its staff as well as to its state-of-theart installations. Confronted with an energy context in transformation and with major scientific advances, it became essential for IREQ to manage explicitly, not only its innovation projects and its research activities, but also its creativity. This article draws upon projects and research to meet this challenge during the last five years at IREQ, where the author is responsible for strategic innovation and creativity.

Based on a survey of its own staff, managers, and researchers, and a benchmarking with similar companies, IREQ has identified a number of problem areas associated with creativity: 


\section{The Creativity Canvas: A Business Model for Knowledge and Idea Management}

\section{Raouf Naggar}

1. Idea generation is seen as a project proposal exercise.

2. When proposals come from creativity-based activities, the scope is defined and the time allotted is limited - this approach may not lead to the best ideas being generated.

3. When proposals stem from an open call for ideas, only a few of the proposed ideas are used. Because so many ideas are rejected, the motivation to propose new ideas diminishes, and good ideas that are rejected for various reasons end up being lost.

4. When an ideator is busy, they hold on to their idea to retain ownership of it and to ensure that it will not be assigned to other researchers.

5. When searching for options and problem solving during projects, the range of ideas being proposed is limited because the ideas are only coming from the project team.

6. The ideas discovered during a project are not always shared outside the project team.

7. Embryonic ideas do not have an opportunity to develop.

An approach proposed to tackle these problem areas was tested in a pilot project during 2011. Its aim was to recognize creativity as a full-fledged activity that can be performed continuously without necessarily having to be associated with any project. It instituted a storehouse of ideas designed to desynchronize the time when ideas are generated from the time they are used and to favour the sharing of ideas and their development (Naggar, 2010).

The approach used in the pilot project was successful to an extent given that it gathered together many participants within IREQ's staff who supported it, but it also revealed new difficulties (Naggar, 2012):

1. It was assumed that, in stimulating the generation of ideas, the approach would encourage the participants to share the challenges that the teams face in their daily work and identify challenges considered important for the company. However, in mind of the participants, it is management's responsibility to identify the challenges that are important to the company, whereas the scientific challenges are under the responsibility of the teams responsible for projects and do not need to be shared.
2. The process called for ideas and project proposals to be kept in a storehouse of ideas. However, the participants saw no advantage in publishing their proposals in an impersonal storehouse and running the risk of missing opportunities; instead, they would rather pitch their proposals directly to the decision makers. It also appeared that the participants did not consider the effort required for the formulation of the ideas in a long-lasting and shareable format to be worth investing considering that the expected profit is uncertain and long term.

3. The pilot project was designed around informal work, realized in the community around ideas proposed by the participants. But, it appeared that the simple act of proposing the ideas was already difficult because people were already overloaded within the framework of the formal projects. Furthermore, the participants were reluctant to share their ideas (except within their trust network) or to discuss them in public. Also, the motivation for informal work with a widened community seemed difficult to reconcile with the entrepreneurial spirit resulting from a system in which recognition is based on the impact of the realizations.

4. The process called for the numerous ideas identified during the projects to be collected so that they could be reused in other projects. However, participants found it difficult to spend time on this activity because no budget was allocated to it and, usually, projects are rather tight in time and budget.

In summary, there were three main obstacles to any attempt to manage knowledge and ideas:

1. Reluctance to share knowledge and ideas beyond a trust network and to face exposure to criticism and competition

2. Lack of motivation to disclose and share knowledge and ideas when there are other priorities and there is no personal benefit from doing so

3. The additional effort required to share knowledge and ideas beyond the work and the projects to which one is already assigned

In earlier studies (Harvey et al., 2013; Naggar et al., 2014), we examined management paradoxes associated with these difficulties and presented some ways to overcome them. 


\section{The Creativity Canvas: A Business Model for Knowledge and Idea Management}

\section{Raouf Naggar}

The present article, however, addresses the problem using a different approach. It proposes that what must be developed is a knowledge and idea management system designed as a coherent ecosystem that takes all controlling factors into account and is based on stakeholder interest and preferences. It is the set of processes, people, tools, and ways to get organized that we call the "system". And, it is because we want this system to function naturally that we say it is an "ecosystem". Yet, we noticed that a good design of this ecosystem needed to take into account the same elements that, generally, must be taken into account in a business model. In fact, a business model approach includes not only developing a value proposition for knowledge and idea management that suits the target clientele but also a good understanding of the resources and activities required to deliver this value proposition and especially the ways to finance them.

It was following a conference presentation by Yves Pigneur in Montréal in 2013 (Pigneur 2013) - in which he presented the business model canvas he developed with his colleague Alexander Osterwalder at Université de Lausanne (Osterwalder et al., 2010, 2011) - that IREQ started to experiment this approach for strategic innov- ation project proposals. The interest of this approach was that it systematically considers each of the conditions for the success of a project, especially getting the support of the targeted customers. From this experience emerged the idea that the business model canvas could also apply to the knowledge and idea management system itself, where the targeted customers are the persons involved in the system and thus the stakeholders of the ecosystem we want to create.

Each of the remaining sections of the article corresponds to one or several sections of the canvas. First, we are interested in the profiles and the motivations of the stakeholders, and we present the value that this ecosystem proposes to each of them. Then, we identify the key activities that are essential for the system in order to keep its promises. We are then interested in what will make these activities possible, that is, the resources and the key partners, the type of relationships to be maintained with and between stakeholders, and the channels by which the value will be obtained. Finally, we determine the cost associated with the functioning of the system and the way it could be financed. Figure 1 presents this economic model, which will be explained in greater detail in the sections that follow.

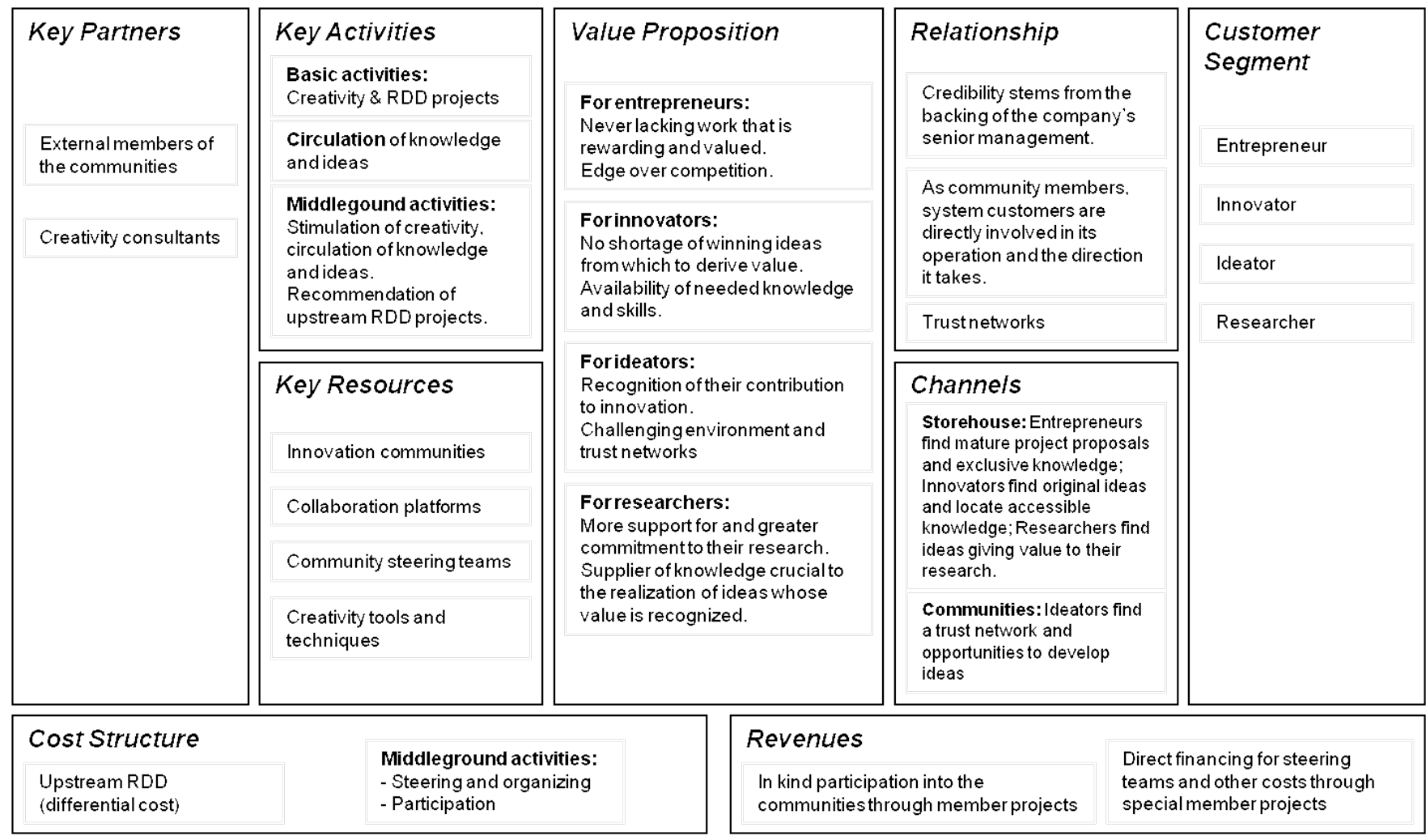

Figure 1. The knowledge and idea management business model, which is based on the business model canvas by Osterwalder and Pigneur (Osterwalder et al., 2010, 2011) 


\section{The Creativity Canvas: A Business Model for Knowledge and Idea Management}

Raouf Naggar

\section{Customer Segments: Stakeholder Profiles and Motivations}

When motivating stakeholders to embrace a technological innovation process, the first thing to do is try to understand what motivates them and what worries them. Each stakeholder, researcher, technician, or manager, can be described by a combination of four typical profiles, which we have illustrated in Figure 2 according to the principles expressed by Sole Parellada (2012) in his works on creativity in small and medium-sized enterprises:

1. The researcher's motivation is the advancement of science and technology by the development of new knowledge. The researcher is worried about the level of support they will receive in their quest.

2. The ideator's motivation is the discovery and creation of opportunities from existing and future knowledge. The ideator is worried about the value granted to their ideas and by the fact that recognition does not go to the person who had the good idea but to the one who has realized it.

3. The innovator's motivation is the creation of value by using knowledge and turning ideas into realities. The innovator is worried about the quality and the relevance of the ideas that are proposed. This profile is typical for a portfolio manager or a project manager.

4. The entrepreneur's motivation is acquisition of projects and the benefits of carrying them out (e.g., success, recognition, compensation.) The entrepreneur is worried about the risk of not having enough projects and of losing precious members of their team during the flat periods. This profile is typical for a business unit manager, a team leader, or a natural leader.

\section{Value Proposition: Benefits for Every Stake- holder}

When knowledge and ideas are successfully managed, every stakeholder sees sufficient wins to motivate their active, voluntary participation in the process. Every stakeholder asks: What's in it for me?

1. What's in it for the entrepreneur? Never lacking work that is rewarding and valued. Successful idea management means customers are enticed by what is offered and want it to be available. Successful know-

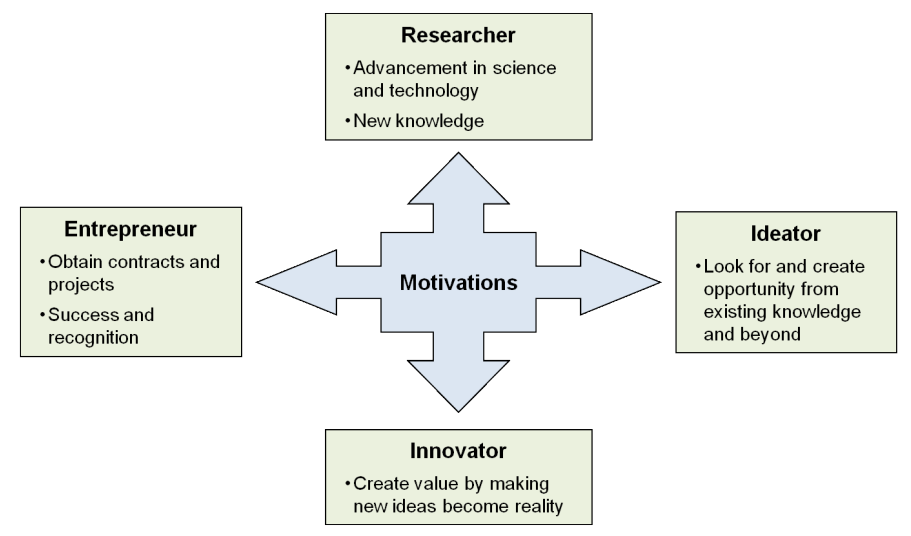

Figure 2. Stakeholder motivations in the ecosystem

ledge management gives the entrepreneur an edge over the competition and the skills to carry out their projects.

2. What's in it for the innovator? No shortage of winning ideas from which to derive value plus the certainty that they can become innovations, given that the knowledge required is available and has been mastered.

3. What's in it for the ideator? Recognition of their contribution to innovation and an environment rich in new challenges where their ideas can thrive, grow, and develop in trust networks, and where they can find opportunities for their realization.

4. What's in it for the researcher? More support and greater commitment for their research, because it is associated with ideas whose value is recognized and because they are the supplier of the knowledge crucial to the realization of these ideas.

\section{Key Activities: Concept-Knowledge Dynamic}

Concept-knowledge (C-K) theory was developed at Mines Paris Tech under the direction of Armand Hatchuel (2010), and it teaches us that ideas or concepts (C) are developed by a tree-structured expansion process. One of the main drivers in the generation of new concepts is new or newly remembered knowledge (K). The branch ends of the tree structure of the concept expansion process are, ultimately, the boundaries of what can be conceived. Knowledge, on the other hand, can be represented as an archipelago composed of islands, each corresponding to a field of knowledge that develops separately. By developing knowledge and making 


\section{The Creativity Canvas: A Business Model for Knowledge and Idea Management}

\section{Raouf Naggar}

connections between the knowledge islands, the boundaries of what is conceivable may be pushed back. (Hatchuel, 2010; Le Masson et al., 2014).

As shown in Figure 3, a variety of activities drive the concept-knowledge dynamic suggested by C-K theory. Here, there is a distinction between three main types of activities: i) the informal "underground" activities that are freely realized by the stakeholders without intervention of management; ii) the formal "upperground" activities that are financed and managed by the company; and iii) the facilitating "middleground" activities that are favoured and supported by the management but they aim at stimulating and at directing the informal activities. The activities illustrated in Figure 3 can be summarized as follows:

1. To start, there are the two basic activities of C-K theory: creativity, or the generation of ideas, and research, development, and demonstration (RDD), which consists of developing or acquiring new knowledge.

2. Next, there is the activity essential for connecting creativity and RDD: the circulation of knowledge and ideas so that a storehouse of knowledge and ideas can be constituted, shared, used, and developed. This activity also aims at integrating external knowledge and ideas. Nonaka and Takeuchi's four modes of knowledge conversion (socialization, externalization, combination, and internalization) find their place in this activity (Nonaka et al., 1995).

3. Ideas and knowledge acquisition flourish among the various players involved in technological innovation. These players manage their ideas and knowledge themselves, sharing depending on their interests and their passions. To obtain results, however, this underground activity needs middleground activity: the organization of stimulating events and favourable environments where proximity and diversity are balanced, so people can understand one another yet find their imaginations stimulated and their horizons broadened. Middleground activities also bring together the different people who play a role in the path of an idea (Cohendet et al., 2008, 2010).

4. RDD activities are upperground activities: they require substantial work and funding. In terms of technological innovation, RDD is downstream of ideas, on the path to the creation of value. With respect to knowledge and idea management, however, RDD is also required upstream of ideas, to assist in idea development, growth, convergence, and renewal. RDD thus also needs middleground activities for the selection, development, and acquisition of project financing upstream of technological innovation. Throughout these activities, it is understood that the

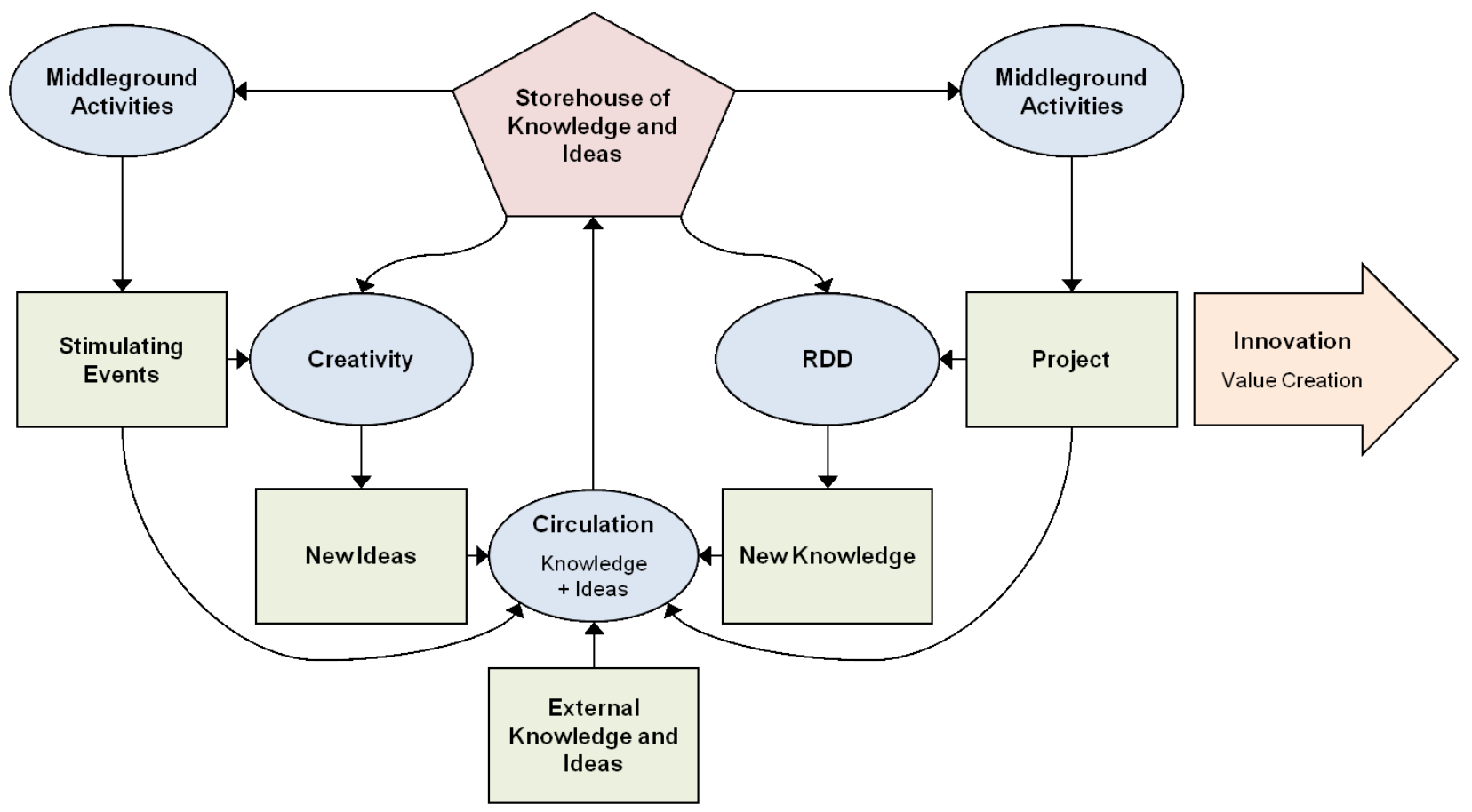

Figure 3. Required activities driving the concept-knowledge dynamic 


\section{The Creativity Canvas: A Business Model for Knowledge and Idea Management}

Raouf Naggar

purpose of research is to discover and understand; the purpose of development is to model, deduce, and design; and the purpose of demonstration is to convince.

\section{Key Resources, Partners, Relationships, and Channels: The Role of Communities}

\section{Key resources}

Underground activities require no dedicated resources. Though upperground activities require the complete array of resources that RDD demands, nothing new is required because we are already in a technological innovation context.

Middleground activities to stimulate creativity, disseminate knowledge, and conduct RDD upstream, on the other hand, require new types of resources:

1. A whole set of innovation communities, large and small, specialized and all-embracing, serving as sites for middleground activities and keepers of the storehouse of ideas and knowledge, explicit as well as tacit, distributed among the communities. Community members must see these communities as a trust network, where they are not only willing to share but feel it is in their interest to do so.

2. A collaboration platform where each community has its own space, where the tacit becomes explicit, the precarious becomes permanent, and contributions are traceable. This platform allows and facilitates communication without regard for distance or time, and serves as the support for the storehouse of knowledge and ideas.

3. Community steering teams that keep the communities active. Each community is autonomous in this respect, but collaboration among the steering teams of the different communities is crucial.

4. Creativity tools and techniques for productive exercises within the communities.

\section{Key partners}

Besides the research institute's resources, the knowledge and idea management system should include external members within its communities. These members, coming from the scientific community, from the user community, or from the supplier community, shall enrich the sharing by bringing different points of view, new knowledge, and original ideas.
It could also be necessary to invite creativity specialists, because various methods are constantly in elaboration to favour the emergence of the ideas.

\section{Relationships}

The communities ensure the relationship between the knowledge and idea management system and stakeholders, that is, the management system's customers. As community members, system customers are directly involved in their community's operation and the direction it takes, making sure it operates in their interest and delivers value to them.

Also of great importance is the credibility of the community, among community members as well as within other communities. This credibility stems from the backing of IREQ's senior management, or outside the context of IREQ, decision makers in general. Such backing is expressed through communication of issues, challenges, and opportunities and responsiveness to the communities' recommendations and proposals.

Finally, the relationships between the stakeholders are solidified within the framework of trust networks, where it is possible to gradually share one's knowledge and ideas, at first in a personal network, then in wider communities. Although this approach may appear to favour secretive actions rather than sharing, our experience is the opposite. This paradox is explained by the interest that stimulates sharing and not the obligation to reveal. This interest will constantly be revived by the middleground activities and will leave to each stakeholder the choice of playing its cards at the convenient moment.

\section{Channels}

Channels are the vehicles whereby stakeholders get what they want from knowledge and idea management:

1. Entrepreneur community members find what they want in the part of the storehouse of ideas containing the most mature project proposals, those that have demonstrated their value and credibility and have found customers. Entrepreneurs count on the exclusivity of the knowledge they hold.

2. Innovator community members find what they want in the variety and originality of the ideas in the storehouse, selecting those that can be used to develop innovative projects of great value. Innovators count on the availability of the knowledge required, within and outside the company. 


\section{The Creativity Canvas: A Business Model for Knowledge and Idea Management}

\section{Raouf Naggar}

3. Ideator community members find what they want in the very structure of the communities, a trust network where they can share and develop ideas and a forum for collaboration offering access to developing knowledge and challenges and issues that need solutions. Ideators count on the different opportunities to play their cards and showcase their best ideas so they can obtain RDD investments to develop them.

4. Researcher community members find what they want in the ideas that would never have occurred to them and that give value to their work and their passions. Researchers count on the contributions to the permanent storehouse of knowledge made by current and past peers to find those "eureka moments" essential for the advancement of science.

\section{Cost Structure: Middleground Activities and Upstream RDD Projects}

Middleground activities and associated resources are new budget items for IREQ. Upstream RDD projects are not really an additional cost: when not conducted upstream, RDD has to be integrated downstream of innovation projects. It is not the cost that changes but the value of the results obtained.

\section{Revenue Streams: Integration with Existing Processes}

In the context of setting up a process for knowledge and idea management, the notion of "revenue streams" must be understood as being the mode of financing of the process, that is the "revenue" that will cover the operating costs of the process.

It is not a question here of asserting profits expected from knowledge and idea management in order to justify a new budget for that purpose. It is rather a question of designing a setup through which financing comes naturally from structures already available, that is the projects, because the success of the process should be the result of contributions by stakeholders.

The final profit will come from the greater value of the realized projects, including higher generated profits, lesser costs, shorter lead times, technology transfers, startups, etc.

\section{Financing of communities}

The real challenge is not so much the actual funding of innovation communities but rather overcoming the perception that devoting resources to such communities compromises technological innovation activities. It can be difficult to explain that diverting time to community activities actually increases efficiency; some may expect the opposite. One way of overcoming this seeming contradiction is to build real collaboration between projects and innovation communities, as shown in Figure 4.

Projects have approved mandates and correspond to innovation strategies. Projects are carried out by a team and must produce deliverables. Communities bring together members with a common interest, offering a place to share ideas and visions and engage in scientific intelligence activities. To ensure that community activities do not encroach on activities that must be conducted in project mode, the work performed in the community must be an efficiency and quality vector in carrying out projects and developing innovation strategies. This happens by building on creativity and knowledge dissemination/capitalization activities.

However, to ensure this works as it should, the area of interest that the community shares with certain projects must be recognized. Projects should thus be asked to join the community and to contribute to it, helping to move it in a direction that serves project interests and develops vision in the field. Through a project's membership in the community, project team members are authorized to contribute in kind as community members. This type of collaboration ensures that community activities are relevant and that time devoted to them is funded through member projects.

Such indirect funding also preserves the independence of the communities, which have no mandate and no deliverables, only a shared passion and interest, because direct funding would mean the communities would be accountable to their funders. This independence contributes to the creativity and motivation of the communities.

Note that, to promote openness and diversity, a community must integrate members from outside IREQ as well as members working on internal projects.

\section{Upstream RDD funding}

Plans for the financing of innovation often include funding of upstream RDD. These budgets, however, are usually for research in new fields, not for synergy with creativity in existing fields.

It is thus important to convince planners that rearranging the total innovation budget to devote some funds to upstream RDD will mean not only better innovations 


\section{The Creativity Canvas: A Business Model for Knowledge and Idea Management}

\section{Raouf Naggar}

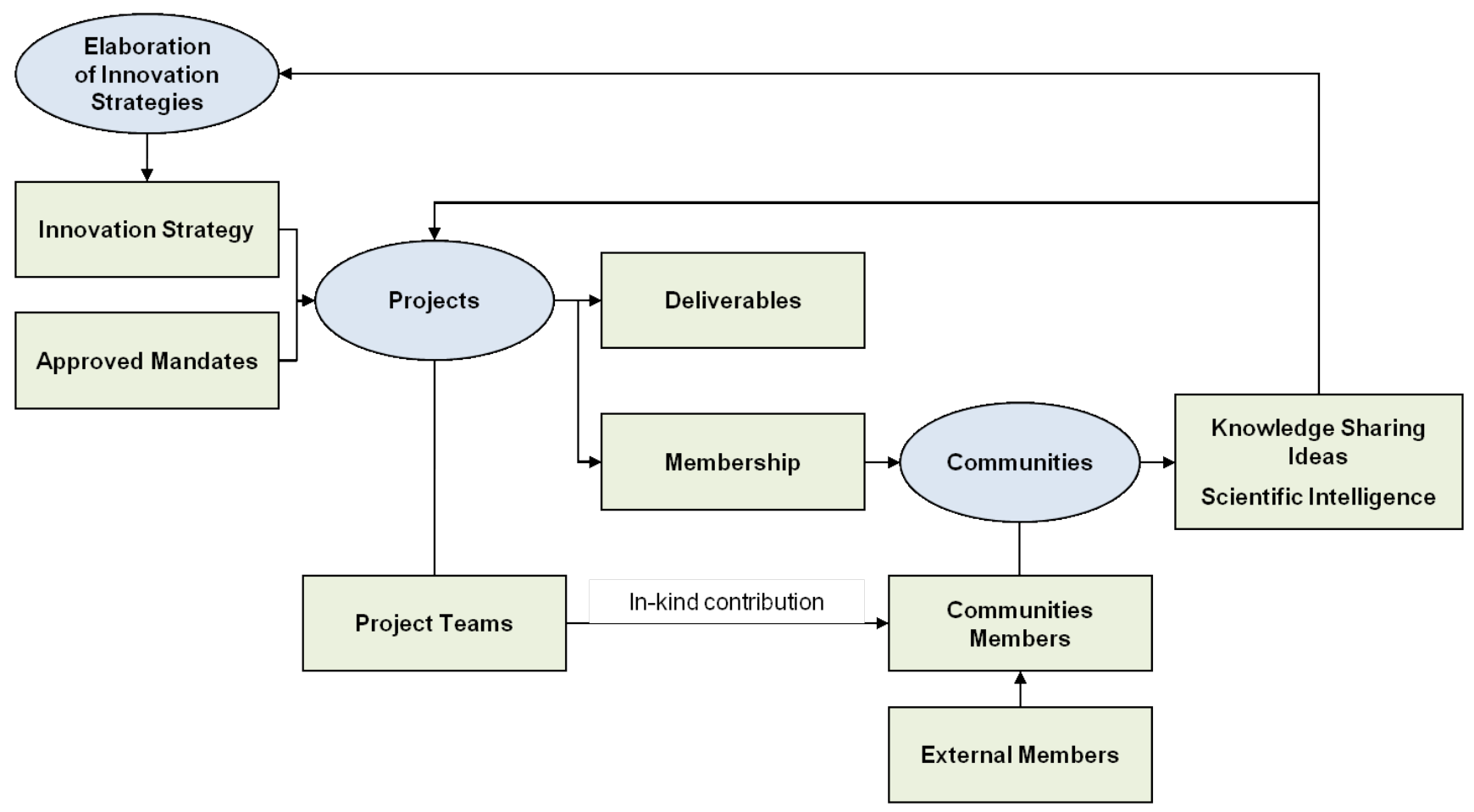

Figure 4. Collaboration between communities and projects

but faster and more efficient innovation development. In other words, such budget reconfigurations could mean a better outcome for zero or perhaps even negative cost. This assertion, however, remains to be demonstrated.

\section{Conclusion}

This article suggests that a coherent ecosystem be developed that takes all controlling factors into account and is based on stakeholder interest and preferences. Key to the development of such an ecosystem is the creation of fully functional innovation communities responsible for "cultivating their gardens", that is, building up and nurturing their ideas and knowledge assets, and deriving value out of the ecosystem. This approach makes it possible to overcome the obstacles identified through IREQ's experiences: reluctance, motivation, and effort. To minimize the required effort, knowledge and ideas may remain tacit, codified only as needed. To recognize and support the effort required, a way of funding participation in communities through ongoing projects is proposed. To motivate stakeholders, the "what's in it for me" is clearly established, and participation is voluntary and geared to topics of importance to participants. Last, to reduce reluctance to participate, a method of disclosure that respects trust networks and contribution traceability is proposed, as is the organization of events providing opportunities to benefit from knowledge and idea sharing.

The business model canvas elaborated in this article summarizes the ecosystem business model proposed for managing knowledge and ideas for technological innovation at IREQ. This model takes into account all factors crucial to the success or failure of such management and provides a coherent picture of solutions developed to handle difficulties encountered by the research institute. It is hoped, however, that the underlying general model can be applied by others to overcome broader problems where creativity plays an essential role but must be reinforced with the knowledge and research that are required to turn ideas into innovations. 


\section{The Creativity Canvas: A Business Model for Knowledge and Idea Management}

\section{Raouf Naggar}

\section{About the Author}

Raouf Naggar is Head of Strategic Development at Hydro-Québec's Research Institute (IREQ), where he is responsible for strategic innovation and creativity. During his career at Hydro-Québec, he has worked as engineer and as researcher in various fields such as: generation and transmission systems planning, power systems reliability, customer service, energy efficiency, system analysis and management, as well as knowledge engineering. He is presently responsible for the institute's Strategic Innovation Projects Portfolio, where upstream RDD is performed. He is also in charge of introducing idea management in the organization. Through this role at IREQ, he became an active participant in Mosaic , the Creativity and Innovation Hub at HEC Montréal.

Citation: Naggar, R. 2015. The Creativity Canvas: A

Business Model for Knowledge and Idea Management.

(c) BY

Technology Innovation Management Review, 5(7):

50-58. http://timreview.ca/article/914

Keywords: creativity, knowledge, ideas, business model, business model canvas, ecosystem, R\&D, technological innovation, communities, research institute

\section{Version Française}

A version of this article is also available in French:

- tinyurl.com/oqkeb3v

\section{References}

Cohendet, P., Llerena, P., \& Simon, L. 2010. The Knowledge-Creating Company in a Creative Industry: The Case of Ubisoft Montreal. Knowledge in Organizations Conference, Monte Verita, Ascona, Switzerland, May 30 - June 3, 2010.

Cohendet, P., \& Simon, L. 2010. Knowledge \& Creativity - Some Basic Concepts. Summer School: Management of Creativity in an Innovation Society, Montréal (QC), Canada, July 3, 2010.

Cohendet, P., Grandadam, D., \& Simon, L. 2008. Réseaux, communautés et projets dans les processus créatifs. Management International, 13(1): 29-44.

Harvey, J.-F., Naggar, R., Cohendet, P., \& Simon, L. 2013. Gérer les idées pour mieux innover. Revue Gestion, 38(3): 25-34.

Hatchuel, A. 2010. C-K Theory: Logic and Management of Innovative Design. Presentation, Summer School: Management of Creativity in an Innovation Society, Barcelona, Spain, July 12, 2010.

Le Masson, P., Weil, B.,\& Hatchuel, A. 2014. Théorie, méthodes et organisations de la conception. Paris: Presses des MINES, Collection Sciences de la Conception.

Naggar, R. 2010. Ideas in a Scientific Environment. 3rd ISPIM Innovation Symposium, Québec City, Canada.

Naggar, R. 2012. Créativité et $R \& D$ dans une entreprise exploitante. Séminaire sur les parcours d'idées et le co-design, HEC Montréal, Canada, August 23-24, 2012.

http://archivesic.ccsd.cnrs.fr/sic_00841503/

Naggar, R., Harvey, J.-F. 2014. Managing Idea. iKnow Magazine, 4(2): 9-11.

Nonaka, I., \& Takeuchi, H. 1995. The Knowledge-Creating Company: How Japanese Companies Create the Dynamics of Innovation. New York: Oxford University Press.

Osterwalder, A., \& Pigneur, Y. 2010. Business Model Generation: A Handbook for Visionaries, Game Changers, and Challengers. Hoboken, NJ: Wiley.

Osterwalder, A., \& Pigneur, Y. 2011. Business model nouvelle génération : Un guide pour visionnaires, révolutionnaires et challengers. Pearson Éducation.

Pigneur, Y. 2013. Business Model Generation. Conference held by Mosaic at École de technologie supérieure in Montreal, Video by HEC - Montréal.

http://tintin.hec.ca/audiovisuel/melies/melies2/visionnement.cf $\mathrm{m}$ ?version $=16107$

Sole Parellada, F. 2012. Creativity in SME. Summer School: Management of Creativity in an Innovation Society, MontréalBarcelona. 